\title{
JEITINHO BRASILEIRO, CONTROLE SOCIAL E COMPETIÇÃO
}

\author{
Fernando C. Prestes Motta \\ Professor-Titular do Departamento de Administração Geral e Recursos Humanos da EAESP/FGV.
}

Rafael Alcadipani

Graduando em Administração na ESPM e em Filosofia na USP e Bolsista do Programa de Iniciação Científica da ESPM.

\section{RESUMO}

O formalismo (a diferença entre o que a lei versa e a conduta concreta, sem que tal diferença implique punição para o infrator da lei) existe em diferentes graus nas mais diversas sociedades do mundo. Tal fato é considerado a principal causa do jeitinho. Entretanto, características socioculturais brasileiras por nós levantadas corroboram com 0 formalismo para a existência do jeitinho em nosso país. 0 jeitinho é 0 típico processo por meio do qual alguém atinge um dado objetivo a despeito de determinações contrárias (leis, ordens, regras etc.). Ele é usado para "driblar" determinações que, se fossem levadas em conta, impossibilitariam a realização da ação pretendida pela pessoa que 0 solicita, valorizando, assim, o pessoal em detrimento do universal. Ele pode ser considerado uma característica cultural brasileira. A cultura é vista como um mecanismo de controle social (Geertz, 1989). Assim, neste artigo, discutiremos como o jeitinho pode ser encarado como controle social pela competição econômica (sucesso) e pelo amor.

\section{ABSTRACT}

The formalism (the difference between the law and what people really do, even if this difference does not cause punishment) exists in different degrees in various parts of the world. It is considered the main cause of the "jeitinho"; however, the characteristics of Brazilian society also take part in this cause. The Brazilian "jeitinho" is the typical process for someone to reach something desired in spite of contrary determinations (laws, orders, rules etc.). The "jeitinho" is used to deceive determinations that would make impossible the aims of the person that asks for the "jeitinho". It makes personal thoughts more important than universal ones. It can also be considered as a Brazilian cultural characteristic. The culture is a social control mechanism (Geertz, 1989). Therefore, we argue that the "jeitinho" can be faced as a social controller through economic competition (success) and through love.

PALAVRAS-CHAVE

Cultura, jeitinho brasileiro, controle social, competição.

KEY WORDS

Culture, Brazilian "jeitinho", social control, competition. 


\section{(...) O que levamos desta vida inútil}

Tanto vale se é

A glória, a fama, o amor, a ciência, a vida,

Como se fosse apenas

A memória de um jogo bem jogado

E uma partida ganha a um jogador melhor

A glória pesa como um fardo rico,

A fama como a febre,

$O$ amor cansa porque é a sério e busca,

A ciência nunca encontra,

E a vida passa e dói porque o conhece...

$O$ jogo de xadrez

Prende a alma toda, mas perdido, pouco

Pesa, pois não é nada (...)

Ricardo Reis (Fernando Pessoa)

Imaginem a cena: sujeito a quase um ano desempregado, casado, três filhos, vivendo do dinheiro de faxinas esporádicas da mulher, descobre que uma loja está precisando de carregador. Vai até a loja, conversa com o dono, que gosta muito dele. Existem mais 13 pessoas na busca pela vaga. Depois de conversar com a esposa do dono da loja, consegue o emprego. Para tanto, precisa estar na loja no dia seguinte às 8 horas com a carteira de trabalho, caso contrário, perde a vaga.

Volta para casa feliz e contente com o emprego conquistado. Procura a carteira de trabalho e, para seu desespero, percebe que a perdeu. Como precisa do documento impreterivelmente no dia seguinte, vai à Junta do Trabalho para fazer um novo. Vale destacar que a maioria dos órgãos governamentais do serviço público no Brasil parece retirada de um conto de Kafka, tamanha a lentidão e a "burocracia" que apresenta.

Lá chegando, após ficar duas horas e meia na fila para ser atendido, a funcionária, com um mal humor ímpar, informa que o documento somente ficará pronto dentro de um mês, já que esse é o procedimentopadrão pelo qual todos, sem exceções, devem passar. Nosso personagem fica desesperado e conta toda sua história, com rigor de detalhes, para a funcionária. Ela pára, pensa, repensa e discute, fala que não tem como... Mas, depois da persistência de nosso ex-desempregado, passa o caso dele na frente de todos os demais e consegue a carteira de trabalho em 45 minutos. Ele agradece e vai embora feliz. Para nós, brasileiros, "deu-se um jeitinho" para o ex-desempregado.

O jeitinho acontece todos os dias nos mais diferentes domínios, quer sejam públicos, quer sejam priva- dos. O esclarecimento desse fenômeno é, acreditamos, de vital importância para se compreender a realidade brasileira, sendo que a compreensão dessa realidade é indispensável para todos aqueles que trabalham e pesquisam as organizações locais. O mais interessante para nós é que o jeitinho, conforme abordaremos neste artigo, assume uma faceta de controle social e competição. Para compreendê-lo, faz-se mister apresentar alguns traços histórico-culturais brasileiros.

A formação e estruturação da sociedade brasileira foram marcadas pela exploração máxima dos recursos naturais do país para serem vendidos ao mercado europeu (Holanda, 1973). Tal fato ficou evidente nos grandes ciclos econômicos no Brasil colonial e no início e meados do período republicano (cana-de-açúcar, mineração e café).

\section{No Brasill, os interesses}

\section{pessoais são tidos como mais} importantes do que os do conjunto da sociedade, ocasionando falta de coesão na vida social brasileira.

Aliás, se nos detivermos na análise do nome Brasil, constataremos que ele foi dado pelos portugueses à terra descoberta graças à grandiosa quantidade de pau-brasil aqui encontrada. $\mathrm{O}$ pau-brasil foi o primeiro produto a ser explorado pela metrópole lusa. Dessa forma, dando o nome Brasil para a terra descoberta, a metrópole deixou marcada simbolicamente no nome do país, para sempre, a sua exploração (Calligaris, 1993).

O ímpeto de exploração metropolitana no período colonial fez com que o reino português evitasse o desenvolvimento do país e não levasse em conta as peculiaridades nacionais quando da implementação das estruturas administrativas, sociais e econômicas.

A bem da verdade, a metrópole explorou e pretendia dominar a colônia. Para tanto, moldou-a e geriu-a conforme suas normas, regras e estruturas. O fato de fazer tudo a "imagem e semelhança do reino" fez com que as citadas estruturas aqui implementadas não levassem em conta a realidade brasileira de então (Holanda, 1973). Assim, o Estado que aqui existia não 
defendia os interesses brasileiros e, muito menos, os da população local (Faoro, 1976).

A adoção de modelos de sociedades tidas como desenvolvidas e a imposição de uma elite minoritária sobre a população não ficaram restritas ao período colonial, haja visto que, na monarquia e na república brasileiras, tal fato continuou a ocorrer, sendo que a estruturação político-social brasileira resistiu às transformações fundamentais: a camada dominante continuou a controlar e a dominar a população (Faoro, 1976).

\section{o jeitinho brasileiro é 0} genuíno processo brasileiro de uma pessoa atingir objetivos a despeito de determinações (leis, normas,

\section{regras, ordens etc.) contrárias.}

O Estado sempre funcionou como um braço da elite brasileira e se impôs sobre a população por meio de sua legislação punitiva: o "não pode" da lei sempre submeteu as pessoas ao Estado (DaMatta, 1983).

No que concerne às formas de gerir mão-de-obra, o "cunhadismo" foi a primeira maneira de dominar pessoas para trabalharem a favor dos interesses europeus quando da exploração do pau-brasil. Ele se deu porque, pelo casamento com uma indígena, o esposo passava a ser parente de toda a tribo à qual a índia pertencia e o europeu utilizou-se dessa relação de parentesco, estabelecida por seu "casamento", para fazer com que seus "parentes" índios trabalhassem na extração do pau-de-tinta. Essa relação de dominação era cordial e aparentemente igualitária (Ribeiro, 1995).

Dando um salto na linha do tempo da história brasileira e passando a falar do período canavieiro, o senhor de engenho, senhor absoluto das terras em que se produzia a cana-de-açúcar, exercia seu domínio e tinha suas decisões orientadas por sentimentos afetivos que amenizavam, por um lado, e reforçavam, por outro, sua autoridade, principalmente no que se refere às questões relacionadas com a gestão de seus empregados e escravos (Freyre, 1963). Pulando novamente na linha temporal da história brasileira, se recordarmos, agora, as relações de trabalho e voto no início do período republicano, constataremos que a figura do coronel dominava o quadro social da época e o fazia por meio de afeto e violência.

Dessa forma, relações paternalistas com envolvimentos ambiguamente cordiais-afetivos e autoritáriosviolentos são lugares-comuns na história da formação da sociedade brasileira e, como demonstram Colbari (1995), Bresler (1997), Alcadipani (1997) e Vasconcellos (1995), a existência dessas características ainda persiste nas organizações locais.

De acordo com Holanda (1973), a mentalidade da casa-grande, ou seja, sentimentos próprios da comunidade doméstica, do público pelo privado, do Estado pela família, invadiu os domínios sociais urbanos quando ocorreu a urbanização brasileira e, pelo que acabamos de ver, persiste até os dias de hoje.

Destaca-se, devido primordialmente às relações paternalistas, a "índole" de fundo emotivo (sentimentalista), marcada por relações de amor e ódio que se colocam sobre as atitudes econômico-racionais, como uma característica cultural brasileira. Isso fica evidente nas atitudes de aparência polida tão peculiares aos brasileiros: teme-se ofender os outros, tratar mal, causar brigas etc.

Há ainda, no povo brasileiro, uma aversão aos ritualismos sociais que explicitam as diferenças entre as pessoas, que deixam claras a hierarquia e as desigualdades, quer sejam de poder, quer sejam sociais. O interessante disso é que, de acordo com Holanda (1973), o respeito se dá entre as pessoas em sua peculiaridade no desejo de se estabelecer intimidade, e não quando se explicita a hierarquia, sendo que os rituais e as venerações de reconhecimento explícito de superioridade são repudiados (Holanda, 1973).

Nota-se, no Brasil, a cultura da pessoalidade, ou seja, o grande valor atribuído à pessoa, sendo que o pessoalmente íntimo é colocado, no mais das vezes, sobre o interesse da coletividade: os interesses pessoais são tidos como mais importantes do que os do conjunto da sociedade, ocasionando falta de coesão na vida social brasileira, na medida em que cada um favorece os seus e os membros de seu "clã" em detrimento do interesse coletivo.

Temos consciência da dialética, da diversidade e da complexidade de qualquer cultura. Ao apontarmos algumas características histórico-culturais de nosso país, não pretendemos, em hipótese alguma, transmitir uma visão reduzida e simplificada da cultura brasileira. A apresen- 
tação desses traços servirá como base para a definição e apresentação das características do jeitinho brasileiro.

Passaremos, agora, a analisar o formalismo, apontado na bibliografia como a causa principal do jeitinho.

O formalismo, de acordo com Riggs (1964), é a diferença entre a conduta concreta e a norma que estabelece como essa conduta deveria ser, sem que tal diferença implique punição para o infrator da norma, ou seja, a diferença entre o que a lei diz e aquilo que acontece de fato, sem que isso gere punição para o infrator da lei.

Para definir o conceito de formalismo, Riggs (1964) propôs três tipos ideais de sociedade: difratadas (países desenvolvidos), prismáticas (países em desenvolvimento) e concentradas (países extremamente subdesenvolvidos). O autor apontou a existência do formalismo nos três tipos ideais de sociedade, sendo residual nos extremos e máximo nas prismáticas.

O formalismo ocorre nas sociedades prismáticas devido ao fato de elas dependerem das difratadas e serem compelidas a implementar suas estruturas (sociais, políticas e econômicas), ou seja, a relação de subjugação das difratadas sobre as prismáticas faz com que as últimas implementem as estruturas da primeira. O formalismo se dá uma vez que as estruturas das sociedades difratadas não condizem com a realidade cotidiana das prismáticas, sendo que tal incompatibilidade implica a impossibilidade da aplicação total das estruturas implementadas.

De acordo com Prado Jr. (1948), a discrepância entre a conduta concreta e as normas que pretendiam regular tal conduta sem a respectiva punição (formalismo) estava presente no Brasil desde os tempos da colônia.

A existência do formalismo, segundo Riggs (1964), faz com que as instituições e as pessoas possam dar, negar, vetar e consentir, ou seja, o fato de ocorrer o desrespeito a algumas leis, dentro de uma dada sociedade, faz com que haja uma generalização da desconfiança em torno da validade de todas as demais leis daquela sociedade. É nesse sentido que o formalismo é apontado como a raiz estrutural do jeitinho brasileiro (Abreu, 1982).

O jeitinho brasileiro, como o próprio nome diz, é brasileiro. Dessa forma, além do formalismo, as características culturais brasileiras apontadas no início deste artigo se inter-relacionaram de maneira difusa e concorrem para sua existência.

O jeitinho brasileiro é o genuíno processo brasileiro de uma pessoa atingir objetivos a despeito de determinações (leis, normas, regras, ordens etc.) contrárias.
É usado para "burlar" determinações que, se levadas em conta, inviabilizariam ou tornariam difícil a ação pretendida pela pessoa que pede o jeito. Assim, ele funciona como uma válvula de escape individual diante das imposições e determinações.

\section{Diferentemente da corrupupçáo, a concessão do jeitinho não é incentivada por nenhum} ganho monetário ou pecuniário: a pessoa que dá o jeitinho não recebe nenhum ganho material ao concedê-lo.

O jeitinho se dá quando a determinação que impossibilitaria ou dificultaria a ação pretendida por uma dada pessoa é reinterpretada pelo responsável por seu cumprimento, que passa a priorizar a peculiaridade da situação e permite o não-cumprimento da determinação, fazendo assim com que a pessoa atinja seu objetivo.

Quando o jeitinho ocorre, aquele que o concede considera a situação particular que lhe foi apresentada como mais importante do que a determinação que deveria ser genérica e, dessa forma, reinterpreta a validade da determinação universal e prioriza o caso específico, ou seja, o pessoal passa a ser mais importante que o universal.

Para consegui-lo, o pretendente deve ser simpático, humilde e mostrar como a aplicação da determinação seria injusta para o seu caso. Vale destacar que o jeitinho, segundo Barbosa (1992), é dominante nas relações que deveriam ser intermediadas pela dominação burocrática weberiana, sendo, portanto, dominante nas relações entre as pessoas e o Estado brasileiro, que deveriam ser intermediadas pela legislação genérica-universal.

Diferentemente da corrupção, a concessão do jeitinho não é incentivada por nenhum ganho monetário ou pecuniário: a pessoa que dá o jeitinho não recebe nenhum ganho material ao concedê-lo.

DaMatta (1991) apresentou o "Você sabe com que está falando?" como uma frase corriqueira na socieda- 
de brasileira. Ela é usada por uma pessoa que quer atingir um objetivo e tenta ser impedida por alguém que seja hierarquicamente inferior a ela. Pode-se citar como exemplo o coronel da polícia sem uniforme flagrado em alta velocidade. Quando o policial aplica a multa ao coronel infrator, ele diz a frase, clara ou veladamente, fazendo com que o policial reconheça a superioridade do coronel e não aplique a multa.

\section{Quem concede o jeitinho}

\section{reavalia a justiça de leis}

\section{e normas, que muitas}

\section{vezes são vistas como}

\section{inadequadlas $\mathrm{e}$}

\section{extremamente impositoras.}

O "Você sabe com que está falando?" deixa claro as diferenças de status na sociedade brasileira e é diametralmente oposto ao jeitinho brasileiro, que, aparentemente, mascara as desigualdades e diferenças, já que o status da pessoa que o solicita não é levado em conta no momento de concedê-lo. Barbosa (1992) afirmou que todos, independentemente da posição que ocupam na sociedade, podem conseguir o jeitinho. O jeitinho também difere da malandragem, na medida em que ela pressupõe que uma pessoa prejudique outra diretamente ou leve vantagem sobre ela. Tal fato não se dá no jeitinho, pois nele se deixa de levar em conta o coletivo e não se dá o prejuízo direto de um sujeito.

Quem concede o jeitinho reavalia a justiça de leis e normas, que muitas vezes são vistas como inadequadas e extremamente impositoras. Além disso, aquele que o concede tem seu poder discretamente fortalecido, na medida em que passa de um simples cumpridor da lei para um avaliador de sua pertinência e aplicação.

O jeitinho brasileiro, como vimos, possui muitas de suas raízes nos traços culturais brasileiros e é, em si, uma instituição cultural da sociedade brasileira.

Qual seria, então, o papel da cultura, como um todo, em uma sociedade?

“(...) A cultura é melhor vista não como complexos de padrões concretos de comportamento - costumes, usos, tradições, feixes de hábitos - como tem sido o caso até agora, mas como um conjunto de me- canismos de controle - planos, receitas, regras, instituições - para governar o comportamento (...)" (Geertz, 1989). Assim, pode-se perceber o papel da cultura como sendo o de um mecanismo de controle. Bresler (1993, p. 48) colocou que “(...) cultura é um conjunto de mecanismos de controle socialmente construído, não é imposto por nenhum ser (sobrenatural ou não) (...)", sendo que os elementos culturais compõem esses mecanismos de controle. Dessa forma, como instituição cultural brasileira, o jeitinho pode ser encarado como um mecanismo de controle social que foi socialmente construído.

Como instituição cultural, ele faz parte da moral brasileira, sendo que, quando uma situação difícil se apresenta a um brasileiro, ele espera "dar um jeito" para resolvê-la. Destacamos que todos sabem de sua existência e quase todas as pessoas tentam se utilizar dele quando necessário.

O jeitinho é uma forma particular (pessoal) de as pessoas resolverem seus problemas dentro da sociedade brasileira sem a alteração do status quo, pois, como cada um resolve seu problema de forma individual por meio dele, não se questiona $\mathrm{e}$, portanto, não se altera a ordem estabelecida.

Se todas as leis, normas, regras, determinações etc. fossem cumpridas com o máximo rigor, seguramente teríamos uma sociedade em paralisia ou explosiva. Tal fato pode ser demonstrado pelas "operações-padrão".

Uma "operação-padrão" acontece quando os funcionários de uma dada organização realizam suas funções estritamente de acordo com as normas que determinam como tal função deveria ser realizada, ou seja, seguem a normatização à risca.

Há algum tempo, os funcionários das linhas de trens suburbanos da Grande São Paulo realizaram uma dessas "operações". De acordo com as normas da ferrovia, os trens que não tivessem extintores de incêndio em um dos vagões ou que, por exemplo, apresentassem pequenos problemas elétricos não poderiam circular. Além disso, em alguns trechos da ferrovia, os trens deveriam circular em uma velocidade bastante baixa, por exemplo. Sempre existiu uma infinidade de normas que não eram cumpridas, parcial ou integralmente, no funcionamento cotidiano da ferrovia. Na citada "operação-padrão", os funcionários seguiram todas as normas minuciosamente. $\mathrm{O}$ resultado foi que pouquíssimos trens circularam e os atrasos foram monumentais. A população ficou revoltada com a demora e depredou inúmeras estações.

Pelo que expusemos, o jeitinho auxilia na manu- 
tenção do status quo e, conseqüentemente, na manutenção do domínio do Estado que gere essa sociedade, tendo um claro papel de controle social.

Podemos classificar em seis os modos de controle social: o controle organizacional (pela máquina burocrática), o controle dos resultados (pela competição econômica), o controle ideológico (pela manifestação da adesão), o controle do amor (pela identificação total ou expressão de confiança), o controle pela saturação (um só texto repetido indefinidamente) e o controle pela dissuasão (instalação de um aparelho de intervenção) (Enriquez, 1990).

Acreditamos que o controle social pela competição econômica e o controle pela identificação total ou expressão de confiança se prestam mais à compreensão da dinâmica do jeitinho brasileiro, lembrando que, no primeiro caso, o que é realmente importante para os indivíduos, grupos ou organizações é o sucesso na vida ou nos negócios.

É esse sucesso que deve ser reconhecido e invejado pelas outras pessoas ou agentes. É o sucesso de qualquer forma indispensável para se manter na corrida com uma vantagem diferencial e não ficar desacreditado.

A competição desconhece limites. Ao contrário, ela se estende a quaisquer domínios: competição entre indivíduos, entre indivíduos e instituições, entre instituições, entre países. Todas as pessoas, todas as organizações, pensando ter uma possibilidade de fazer parte da elite dos vencedores e tendo interiorizado o modelo de luta, aceitam a competição como regra, o que confere à vida pública e privada seu caráter de espetáculo e teatralidade. Tudo se passa para que, como no final de todo melodrama, os bons vençam e os maus sucumbam. Pelo menos é assim que se espera que as coisas se passem. De qualquer modo, nenhuma comiseração é dirigida aos vencidos, no máximo piedade ou desprezo. Viva os vencedores e ai dos vencidos: Estas são palavras finais (Enriquez, 1990).

O controle do amor é aquele que se dá pela identificação total ou expressão de confiança. Evidentemente, pode-se pensar que se trata mais uma vez da enorme importância dos vínculos libidinosos entre chefes e massas dependentes (Freud, 1981). Todavia, trata-se de dois modos básicos de funcionamento do discurso amoroso: o fascínio (que está perto da hipnose) e a sedução.

Está em jogo no fascínio a possibilidade que os homens têm de se perderem e se encontrarem em um ser. Trata-se aqui da fusão amorosa com o ser fascinante, por meio da qual o indivíduo deixa de lado o seu invólucro corpóreo para se tornar parte do "grande todo", seu ego se dilatando e absorvendo, como faz o bebê, o mundo exterior. O indivíduo torna-se diáfano e, por isso mesmo, um pequeno deus. Perdendo suas referências habituais, ele vai além de si próprio.

\section{Como instituiição culltural}

\section{brasilleira, o jeitinho pode} ser encarado como um mecanismo de controle social que foi socialmente construído.

Teatral e diretamente, o ser fascinante apresenta ao pequeno homem o que ele poderia vir a ser. É assim que este vive por delegação do seu heroísmo escondido. O ser fascinante devolve-lhe seu desejo mais profundo de ser reconhecido, identificado, amado, podendo levá-lo a transformar-se e a transcender-se.

O ser que fascina é o manipulador e o perseguidor, mas também é sobretudo o que chamamos de "ascensor" e "anunciador". Ele é ascensor porque nos chama a seu nível e nos permite encontrá-lo. É ele também que anuncia a boa nova: o sonho de cada um pode ser a realidade, já que todos podem ser deuses, como o ser fascinante (Enriquez, 1990).

No caso da sedução, é outra coisa que está em jogo. É na aparência e no jogo das aparências que reside a sedução. O discurso pronunciado não precisa significar nada e nem mesmo convidar à ação. $\mathrm{O}$ discurso se apóia sobre outras coisas, sobre palavras bem escolhidas, sobre frases bem equilibradas, sobre fórmulas chocantes, sobre uma dicção evocadora, sobre um sorriso que alicia, sobre uma capacidade de banalização dos problemas, sobre idéias gerais e generosas que em si mesmas não provocam desacordo e que são criadas para não perturbar.

A palavra sedutora é uma palavra sem asperezas, de tal forma que o seduzido não se sente forçado. Ele é atraído pela aptidão de tornar os problemas sem dramas, pelo tom ao mesmo tempo próximo e distante. Não há vítimas. O sedutor está consciente de que a sedução é parte da mentira e o seduzido sabe que o objetivo dessas palavras é apaziguá-lo. 


\section{A competição desconhece}

\section{limites. Ao contrário, ela}

\section{se estende a quaisquer}

\section{domínios: competição entre} indivíduos, entre indivíduos e instituições, entre instituições, entre países.

Entretanto, existe um outro lado mais recôndito da sedução. É a sedução que violenta. É que, ao jogar consigo próprio, o sedutor joga ao mesmo tempo com e contra o outro. Ele tenta amordaçar e alienar o outro o mais profundamente possível e fugir da armadilha que ele mesmo construiu. É assim que Don Juan não pode se apaixonar. Ao contrário, ele deve passar de uma mulher a outra sem ser tocado pelos sentimentos.

$\mathrm{Na}$ verdade, o que o sedutor esconde sob seu sorriso é uma máscara de destruição e desprezo. A compreensão desse fato é clara na teoria da sedução de Freud (1981). O trauma é da autoria do sedutor, que, de fato, é o pai da neurose. Quem é o sedutor se não aquele que enlouquece o outro, que desperta a sua perdição de corpo e espírito?
É dessa forma que o jogo, que era divertido e sutil, se torna também sinistro. Os fascinadores são muitas vezes tão perigosos quanto os grandes sedutores políticos, mas isso não se percebe tão facilmente. Sedutor por excelência, John Kennedy concordou com o desembarque na Baía dos Porcos, em Cuba, além de ter preparado o fracasso dos Estados Unidos no Vietnã.

Lembra-se sempre de Don Juan e Casanova com um sentimento caloroso. É a face rosa a que fica e não a negra. A razão é simples: não se acredita que o fascinador possa se fascinar por alguém, mas acredita-se que o sedutor possa ser seduzido. Da sedução ao amor, mas também ao ridículo, é um passo.

No caso do jeitinho brasileiro, tanto o solicitante quanto o concedente competem com o Estado. O primeiro quando burla a norma e o segundo quando a avalia. Em ambos os casos, o Estado pode parecer como ser fascinante. Em segundo lugar, o solicitante e o concedente competem entre si. O solicitante usa o poder da sedução e o concedente responde com o poder da autoridade.

Além disso, os solicitantes competem entre si pelo poder de seduzir e eventualmente pelas relações sociais que colocam em jogo para atingir seus objetivos. Também os concedentes competem entre si pela possibilidade de dar o jeitinho. Nesse caso, competem pela autoridade formal, pela liderança ou pelas relações sociais. $\bigcirc$

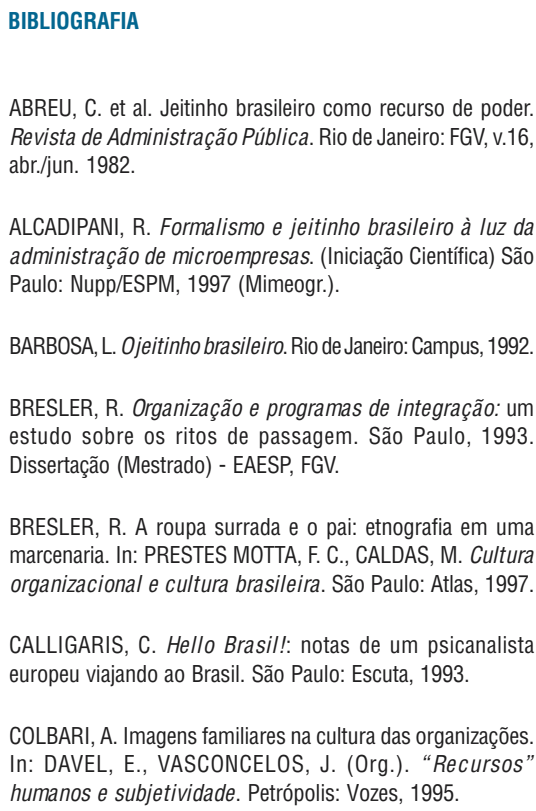

BRESLER, R. A roupa surrada e o pai: etnografia em uma marcenaria. In: PRESTES MOTTA, F. C., CALDAS, M. Cultura organizacional e cultura brasileira. São Paulo: Atlas, 1997.

CALLIGARIS, C. Hello Brasil!: notas de um psicanalista europeu viajando ao Brasil. São Paulo: Escuta, 1993.

COLBARI, A. Imagens familiares na cultura das organizações. In: DAVEL, E., VASCONCELOS, J. (Org.). "Recursos" humanos e subjetividade. Petrópolis: Vozes, 1995.

DaMATTA, R. Carnaval, malandros e heróis. 5.ed. Rio de Janeiro: Guanabara, 1983.

DaMATTA, R. O que faz o Brasil, Brasil? 5.ed. Rio de Janeiro: Rocco, 1991.

ENRIQUEZ, E. Da horda ao estado: psicanálise do vínculo social. 2.ed. Rio de Janeiro: Zahar, 1990.

FAORO, R. Os donos do poder: formação do patronato político brasileiro. 3.ed. Porto Alegre: Globo, 1976. 2v.

FREUD, Sigmund. Psychologie des foules et analyse du moi. In: Essais de psychanalise. Nouvelle edition. Paris: Petite Bibliothèque Payot, 1981.

FREYRE, G. Casa-grande \& senzala. 12.ed. Brasília: UnB, 1963. GEERTZ, C. Interpretação da cultura. Rio de Janeiro: Guanabara, 1989. HOLANDA, S. B. Raízes do Brasil. Rio de Janeiro: J. Olympio, 1973.

PRAD0 JR., C. Formação do Brasil contemporâneo. 3.ed. São Paulo: Brasiliense, 1948.
PRESTES MOTTA, F. Cultura nacional e cultura organizacional. Revista da ESPM, v.2, n.2, ago. 1995.

PRESTES MOTTA, F. Cultura e organizações no Brasil. São Paulo: EAESP/FGV, 1996. (Relatório de Pesquisa NPP, 15).

RAMOS, A. Administração e contexto brasileiro. Rio de Janeiro: FGV, 1983.

RIBEIRO, D. O povo brasileiro: a formação e o sentido do Brasil. São Paulo: Companhia das Letras, 1995.

RIGGS, F. W. A ecologia da administração pública. Rio de Janeiro: FGV, 1964

VALENTE, J. A certidão de nascimento do Brasil: a carta de Pero Vaz de Caminha. São Paulo: Edição do Fundo de Pesquisas do Museu da USP, 1975.

VASCONCELLOS, J. 0 coronelismo nas organizações: a gênese da gestão autoritária. In: DAVEL, E., VASCONCELOS, J. (Org.). "Recursos" humanos e subjetividade. Petrópolis: Vozes, 1995. 